\title{
Información política televisiva y espectaculariza- ción: un análisis comparativo de programas informativos y de infoentretenimiento
}

\author{
Nel·lo PelLisser Rossell \\ Universidad de Valencia \\ manuel.pellicer@uv.es \\ Antonio PINEDA \\ Universidad de Sevilla \\ apc@us.es
}

Recibido 25 de octubre de 2013

Aceptado: 19 de mayo de 2014

\begin{abstract}
Resumen
Este artículo estudia la tendencia a la espectacularización en el tratamiento de la información política televisiva en España. Realizamos un estudio de espacios informativos, así como una comparación de los anteriores con los contenidos de programas de infoentretenimiento (infotainment). El análisis de los informativos se centra en los canales autonómicos Canal Sur y Canal 9-RTVV, mientras que la muestra de infotainment abarca diez programas procedentes de cadenas tanto privadas como públicas. A partir de un análisis de contenido temático, los resultados indican similitudes entre los informativos y el infotainment en lo relativo a la espectacularización, siendo la personalización el indicador clave. Asimismo, existen diferencias, tanto en la forma en que los canales autonómicos dramatizan la información política, como respecto a la espectacularización en el infotainment.
\end{abstract}

Palabras clave: Espectacularización, Informativos de televisión, Infoentretenimiento, Información política

\section{Television Political Information and Spectacularization: A Comparative Analysis of Newscasts and Infotainment Programs}

\begin{abstract}
This paper focuses on the trend toward spectacularization in political information that is broadcast on Spanish television. We perform a study of newscasts, and we compare the newscasts with the content of infotainment programs. The analysis of television newscasts centers on two Spanish regional channels: Canal Sur and Canal 9-RTVV. The infotainment sample comprises ten programs collected from both private and public TV channels. A thematic content analysis provides data that indicate similarities between newscasts and infotainment programs with regard to spectacularization, being personalization the key indicator in this respect. At the same time, there are differences regarding the way regional channels dramatize political information, as well as differences pertaining to spectacularization in infotainment programs.
\end{abstract}

Keywords: Spectacularization, Television newscasts, Infotainment, Political information

1 Este trabajo recoge resultados del proyecto de investigación Televisión y Deliberación Política. La construcción del espacio público a través de los géneros de la realidad en España (TEDEPO), desarrollado por la Universitat Pompeu Fabra, la Universidad de Sevilla y la Universidad de Valencia, y financiado por el Ministerio de Ciencia e Innovación (Plan de $\mathrm{I}+\mathrm{D}+\mathrm{i}$ 2008-2011, ref. CSO2008-02589). 


\section{Referencia normalizada}

PELLISSER ROSSELL, Nel·lo y PINEDA, Antonio (2014): “Información política televisiva y espectacularización: un análisis comparativo de programas informativos y de infoentretenimiento". Estudios sobre el Mensaje Periodístico. Vol. 20, Núm. 2 (julio-diciembre), págs.: 821-839. Madrid, Servicio de Publicaciones de la Universidad Complutense.

Sumario: 1. Introducción: espectacularización mediática e infotainment. 2. Espectacularización y contexto de producción en Canal Sur y Canal 9. 3. Hipótesis y metodología. 4. Resultados. 5. Discusión. 6. Conclusiones. 7. Referencias bibliográficas.

\section{Introducción: espectacularización mediática e infotainment}

El fenómeno de la espectacularización suele ser un elemento clave tanto para criticar la producción mediática (especialmente la televisiva), como para garantizar supuestamente el éxito y la rentabilidad de la producción mediática que se pone de manifiesto en los formatos, los contenidos, los programas y las programaciones. Según Imbert:

Más que nunca, la televisión está dividida entre la necesidad de informar -el imperativo moderno del ver-saber todo-y el deseo de espectáculo fomentado por la cultura de masas, la transformación de la realidad en objeto consumible como espectáculo. De ahí la dilución de la categoría de lo informativo.

Hoy, todo es objeto de información-espectacularización, nada escapa al poder-ver mediático: de lo extra-ordinario (el «évènement») en su dimensión histórica, trascendente, hasta lo más ordinario, lo cotidiano, intrascendente. Es la revancha del suceder sobre el acontecer. El bombardeo informativo necesita reactivar constantemente el interés, espectacularizar al máximo el mensaje para «no cansar», «no aburrir»... (2008a: 17).

Mientras que las acotaciones de Imbert (cfr. 2008a, 2008b, 2010) y otros autores (cfr. Postman, 1991; Bourdieu, 1997; Ramonet, 1998, 2000, 2011; Kapuscinski, 2002) suponen la constatación, o cuanto menos la percepción, de que se ha producido un proceso de degradación o tergiversación de la naturaleza del espectáculo en la industria televisiva, la espectacularización se presenta simultáneamente en la actualidad, por parte de determinadas instancias, como un recurso ineludible de ciertos formatos y contenidos televisivos. Además, suele ser justificada por los productores de televisión con argumentos como la demanda de la audiencia, la libertad de expresión y creación, o la consideración de esos productos televisivos como una representación coherente, adecuada y eficaz de la realidad social cotidiana.

Mientras que el término y el concepto de "espectáculo" aluden simplemente a construcciones o representaciones realizadas para ser vistas y disfrutadas por los receptores de las mismas -receptores que en muchos casos son también partícipes o copartícipes de dicho espectáculo, ya sea un rito religioso, una fiesta popular, una representación teatral, un concierto de música, una proyección cinematográfica o un programa televisivo (cfr. González Requena, 1985; Pavis, 2008)-, el concepto derivado de "espectacularización" se ha acabado entendiendo como una perversión del espectáculo. Según Eco, el "peor sentido" del término espectáculo implica "una falsa vida representada en el escenario para que los asistentes, silenciosos, tengamos la ilusión de vivir por persona interpuesta" (1986: 239). 
La espectacularización, que en palabras de Imbert (2008b) define la postelevisión, se considera un proceso "que padece la cultura mediática, la televisión; [una televisión que] hoy, ha dejado de ser "ventana al mundo", fiel reproducción de la realidad objetiva, para convertirse en espacio de proyección, espejo del sujeto". Las manifestaciones de estas transformaciones en el medio televisivo son múltiples y afectan a importantes y diferentes aspectos de la producción televisiva (géneros, programas, recursos) tanto en nuestro entorno más próximo como en el global. Según Imbert (cfr. 2008a), la espectacularización es uno de los factores fundamentales (no el único) que explican la caracterización de la televisión actual por haber pasado de la telerrealidad a la teleidentidad, haber cambiado sus funciones sociales, practicar el transformismo y deformación, difuminar la frontera entre información y ficción (espectáculo), eliminar los valores éticos, sociales, estéticos, morales y simbólicos, y, finalmente, implantar el dominio del simulacro. Por otro lado, Ramonet (2000: 23) afirma: "El reproche fundamental que puede hacerse hoy a la información es el de su espectacularización, la búsqueda del sensacionalismo a cualquier precio, que puede conducir a aberraciones, mentiras y trucajes". Y Kapuscinski denuncia la mercantilización de la información en conexión con el fenómeno de lo espectacular (cfr. 2002: 36).

Estrechamente relacionado con el concepto de espectacularización se encuentra la dramatización. Según Ramonet: "Inevitablemente, el telediario da prioridad a las imágenes espectaculares -incendios, disturbios, violencia en las calles, catástrofes, guerras- y, condicionado por esa selección, realizada en nombre de la calidad visual, se ve condenado a favorecer lo anecdótico y los superfluo, a especular con las emociones insistiendo en la dramatización" (1998: 91). Según esta perspectiva, la dramatización podría entenderse como una consecuencia o recurso emocional de la selección espectacular de elementos informativos.

La tendencia social, económica y política a la espectacularización y la dramatización ha influido en el género híbrido del infotainment (cfr. Carrillo, 2013: 36-37), barbarismo (traducible como "infoentretenimiento") que surge a finales de la década de 1980. El infotainment " [...] refers to an explicit genre-mix of 'information' and 'entertainment' in news and current affairs programming" (Thussu, 2009: 7). Un ejemplo de este tipo de programas sería el talk-show, una fórmula de tertulias o debates que ha tenido una considerable implantación en la televisión española (cfr. Fernández Soriano, 1999: 148-149), y que puede versar sobre temas variados, incluyendo asuntos sensacionalistas. Por otro lado, y en un contexto mediático donde la diferencia entre la función informativa de la televisión y el entretenimiento se hace cada vez menos nítida (cfr. Imbert, 2010: 147-148), el infotainment rebasa sus fronteras naturales y traslada algunos de sus rasgos a los informativos (cfr. Ortells Badenes, 2009). Un concepto similar al de infotainment es el de info-show, definido por Prado como "un macrogénero resultante de las hibridaciones entre formatos del macrogénero información y otros del macrogénero ficción y los demás macrogéneros del entretenimiento como el concurso o el show" (2003: 183). 
El objetivo de la presente investigación es constatar si la tendencia a la espectacularización, así como la difuminación de función informativa y entretenimiento, afecta en particular a la información televisiva de naturaleza política en España. Este objetivo puede formularse según la siguiente pregunta de investigación (PI):

$\mathrm{PI}_{1}$. ¿Qué elementos relativos al fenómeno de la espectacularización mediática se manifiestan en los informativos de televisión españoles?

En un contexto teórico y profesional donde las barreras entre lo informativo y el entretenimiento se difuminan, consideramos lógico realizar una pregunta de investigación adicional:

$\mathrm{PI}_{2} \cdot$ ¿Existen similitudes entre los informativos de televisión y los programas de infoentretenimiento españoles en lo relativo a la espectacularización?

Por otro lado, y puesto que la presente investigación se centra en la información de naturaleza política, una tercera PI adquiere especial interés:

$\mathrm{PI}_{3}$. ¿Qué imagen o concepción de la política surge a partir de la espectacularización de los contenidos en la información y el infoentretenimiento televisivos españoles?

Para responder a estas preguntas, en el presente artículo se lleva a cabo (1) un estudio de la presencia de la espectacularización en programas informativos de televisiones públicas, así como (2) un estudio comparativo de los datos obtenidos a partir de dichos informativos y de los datos procedentes de programas encuadrables en el infotainment televisivo, que en algunos casos son emitidos por cadenas privadas comerciales. De esta forma, perseguimos un análisis empírico de la manifestación de la espectacularización en dos formatos a priori distintos.

Los informativos seleccionados pertenecen a dos canales del Estado español: Canal Sur y Canal 9, televisiones de ámbito autonómico (andaluz y valenciano respectivamente) en cuyos territorios gobiernan opciones de distinto signo político. Merece la pena señalar que este tipo de cadenas supone un objeto interesante para estudiar el fenómeno de la espectacularización y el entretenimiento, dado que, como señala Ramonell, las televisiones autonómicas "tienen que convivir con la contradicción de tener que compaginar una programación de servicio público, deficitaria, con otra de entretenimiento y de marcado carácter comercial, para poder recaudar algunos ingresos con la publicidad" (2006: 37).

Por otro lado, los programas de infotainment objeto de análisis son emitidos en ocho canales de televisión (tanto públicos como privados): Telecinco, Antena 3, Cuatro, TVE1, Canal Sur, Canal 9, TV3 y La Sexta. Además de aportar una panorámica sobre la espectacularización en el infoentretenimiento español, este bloque de programas puede ofrecernos un instrumento comparativo para reflexionar sobre la posible convergencia de las noticias y el entretenimiento; y, más específicamente, para cotejar qué televisión autonómica (Canal 9 o Canal Sur) acerca en mayor medida su tratamiento temático al del infoentretenimiento. En este contexto, consideramos relevante profundizar, aunque sea de manera breve, en el contexto de producción de los dos principales canales sobre los que versa este estudio. 


\section{Espectacularización y contexto de producción en Canal Sur y Canal 9}

Canal Sur Televisión inició sus emisiones regulares la noche del 27 de febrero de 1989. La programación del canal andaluz, que ha cosechado índices razonablemente considerables de share (cfr. Fernández Soriano, 1999: 115-118), es generalista y presenta cierta diversidad: informativos, ficción, deporte, programas infantiles, documentales, concursos... y también info-shows, género que se implanta en las televisiones autonómicas en 1995 y que será adoptado por Canal Sur con especial interés, hasta el punto de que la andaluza es una de las cadenas autonómicas donde mayor peso tiene el info-show (cfr. Fernández Soriano, 1999: 132-134, 148-149). Dentro de este género puede citarse el programa de televisión en directo Tal Como Somos, que se mantuvo 7 temporadas en antena entre 1990 y 1997, y sería sustituido por $\mathrm{An}$ dalucía Directo. En este contexto, podría citarse asimismo el caso del programa Aquí se discute (en antena durante 26 semanas hasta ser retirado el 3 de abril de 1998), al que se ha criticado "su contenido espectacular disfrazado de debate" (Manfredi Díaz y García Hernández, 1999: 190). El 5 de junio de 1998 comienza sus emisiones el segundo canal televisivo autonómico andaluz, Canal 2 Andalucía, que trata de complementar la oferta del primer canal y se dirige a un público joven y urbano, prestando además una atención especial al deporte, el entretenimiento, los contenidos infantiles, los programas medioambientales y, sobre todo, la identidad cultural andaluza (cfr. Montaño Montaño, 1999: 208-210). Tras cambiar su nombre por Canal Sur 2 en 2008, el canal cerró su programación a partir de octubre de 2012, para pasar a emitir “"...] la misma señal que Canal Sur, pero con subtítulos, lengua de signos y audiodescripción de las películas" (González-Santiago, 2012).

Canal Sur TV no ha estado exento de críticas, relativas a aspectos como la calidad de la programación (cfr. Manfredi Díaz y García Hernández, 1999: 187-190; Almansa, 2009). Estas críticas coexisten con el grado de popularidad que experimenta la televisión andaluza, cuyos informativos han llegado a sobrepasar la barrera del $23 \%$ de share (cfr. Ramonell, 2006: 36). En cuanto a la calidad, según Isidoro Moreno "la Andalucía que se nos ofrece en la pantalla es, generalmente, una caricatura de sí misma, mostrándose de ella casi sólo lo más superficial y estereotipado, cuando no directamente lo más chabacano" (2000: 187); de hecho, la propia RTVA observa que el flamenco y los toros "[...] están muy presentes en la oferta de la televisión andaluza" (2009). Un ejemplo del peso de los tópicos andaluces en Canal Sur (y su éxito popular, a tenor de las audiencias) es el concurso Se llama copla, que en 2008 hizo historia cuando la gala final del programa ocupó la franja más vista hasta el momento en la trayectoria de la televisión pública andaluza (cfr. Bioque, 2008); en la final de 2011, el programa volvió a ser líder de audiencia, logrando récord de temporada (cfr. RTVA, 2011).

Por su parte, la Radio Televisión Valenciana (RTVV)-Canal 9, ahora Grup RTVV, inició sus emisiones regulares el 9 de octubre de 1989. Canal 9 tiene en su haber el dudoso honor de ser la televisión que sembró la semilla de lo que se ha denominado "telebasura": Tómbola. Del carácter paradigmático de este talk-show es significativo el hecho de que, coincidiendo con el quince aniversario de su estreno en Canal 9, el diario El Mundo recordaba la efemérides con un reportaje titulado "El cumpleaños de la 
'telebasura"' (12/03/2012). En el mismo texto, Jesús Mariñas, uno de sus colaboradores más representativos, subrayaba el valor simbólico del programa con las siguientes palabras: "Fue la universidad, la catedral y el trampolín de todo lo que se hace ahora". Tómbola estuvo en antena desde el 13 de marzo de 1997 hasta el 25 de noviembre de 2004. Siete años y ocho meses de programa, 383 emisiones y 1.500 horas de televisión en directo. Todo ello con un coste que la oposición cifró en su día en más de 36 millones de euros. El fenómeno Tómbola trascendió el territorio autonómico valenciano. En Telemadrid estuvo en antena cerca de cuatro años, desde marzo de 1997 hasta febrero de 2001. También llegó a Canal Sur, donde sobrevivió unos meses, hasta que desapareció tras la emisión de un polémico especial sobre Lady Di en septiembre de 1997.

La iniciativa de poner en marcha el programa la tomó Jesús Sánchez Carrascosa poco después de ser nombrado director de TVV por el Consell de la Generalitat. Sánchez Carrascosa era amigo de Eduardo Zaplana, jefe de su campaña a la Generalitat y secretario general de Presidencia en su primer mandato. Fue, además, el artífice de diversas iniciativas que, aunque sin la repercusión de Tómbola, respondían a la misma pulsión espectacularizadora, pero trasladada al área de informativos. Entre otras, puso en marcha un mini-concurso que consistía en acertar una pregunta relacionada con alguna de las informaciones que se ofrecían en los boletines horarios que emitían en Noticies 9, el segundo canal. El espacio llevaba por título "A cent mil per hora", en referencia a la cuantía del premio, que era de cien mil pesetas. También introdujo rótulos publicitarios en pantalla durante la emisión del informativo, suprimió los contenidos culturales y los sustituyó por un micro espacio de crónica social y del corazón y propuso ofrecer primas a los periodistas que cada día consiguieran "la mejor noticia". Todo ello provocó las protestas del nuevo Comité de Redacción, una vieja aspiración de los periodistas de la casa, puesto en marcha por aquellas fechas. La respuesta de la dirección a las protestas reiteradas del Comité fue la contratación de 54 redactores, la mayor parte de ellos sin experiencia. Con esta contratación, supuestamente para conformar la redacción del inminente segundo canal, en realidad lo que se hizo fue sustituir un parte significativa de los redactores de Canal 9, que fueron trasladados a distintas secciones o programas. Tras años de abundar en la banalización y la degradación de los contenidos, con la consiguiente pérdida de audiencia y de descrédito entre la ciudadanía, y paralelamente a una gestión económica nefasta y opaca, la televisión pública valenciana ha sido abocada al colapso.

\section{Hipótesis y metodología}

A partir del marco teórico, y tras abordar los contextos de producción de las principales cadenas objeto de este estudio (y su tradición de espectacularización), proponemos la siguiente hipótesis, que trata de responder en particular a la pregunta de investigación $\mathrm{PI}_{2}$ :

$\mathrm{H}_{1}$. Los informativos de televisión y los programas de infotainment españoles presentan indicios similares de espectacularización.

Las respuestas a $\mathrm{PI}_{1}$ y $\mathrm{PI}_{3}$, por su parte, se obtendrán mediante el análisis y discusión de los resultados empíricos. Para ello, la metodología utilizada en el presente 
trabajo es la del análisis de contenido cuantitativo (cfr. Igartua, 2006), en tanto que "conjunto de técnicas de investigación empírica, destinadas a estudiar los contenidos recurrentes de una determinada muestra de texto (en este caso televisivos)" (Casetti y di Chio, 1999: 235). Dentro de las diversas unidades que el análisis de contenido cuantifica, nos centramos en unidades de tipo temático, debido a su riqueza descriptiva (cfr. Krippendorff, 2004: 107-109).

La dramatización de la información puede llevarse a cabo mediante recursos formales (cfr. Imbert, 2010: 147-148). En esta investigación nos interesa más bien cuantificar la tendencia a la espectacularización mediante recursos conceptuales; concretamente, mediante la selección y tratamiento de temas. Este recurso es especialmente pertinente dados nuestros objetivos de investigación, ya que el tratamiento de los temas ha sido considerado uno de los componentes del espectáculo (cfr. Bernardo y Pellisser, 2010: 31-32). Por consiguiente, el eje del análisis radica en el tratamiento televisivo de los temas. Para analizar en qué medida un tema y su tratamiento se sitúan bajo la lógica de la espectacularización, hemos operado con una serie de índices de espectacularización. Por ejemplo, puede mencionarse la utilidad que para definir la espectacularidad temática tiene el concepto de noticias ligeras o soft news (derivado del estilo estadounidense de información televisiva), centradas en famosos, delincuencia, corrupción y crimen (cfr. Ramonet, 1998: 90; León, 2010: 23), frente a las noticias "duras", relativas a la política (cfr. Ortells Badenes, 2009). En el infotainment global (cfr. Thussu, 2009: 8), las soft news son presentadas como una forma de espectáculo.

Los índices de espectacularización se han obtenido de autores como Bourdieu (cfr. 1997: 25), Ramonet (cfr. 1998: 91, 95), Díaz Nosty (cfr. 2006: 21-24), Ortells Badenes (cfr. 2009), León (cfr. 2010: 23), y Bernardo y Pellisser (cfr. 2010: 38), y son los siguientes ${ }^{2}$ :

- Contenidos de soft news: famosos, delincuencia, corrupción y crimen (por encima de los asuntos políticos, cívicos y públicos).

- Búsqueda de la parte más "humana" de la información (por encima del interés público).

- Personalización de los temas (por encima de la consideración estructural o abstracta de los mismos).

- Sensacionalismo (por encima del juicio calibrado).

- Escándalo (sentimiento ante una conducta desvergonzada).

- Vida social y mundo de la farándula

- Banalización y trivialidad (por encima de lo relevante).

- Lo anecdótico (por encima de lo prioritario y sustancial).

- Superficialidad (por encima de la profundidad en el tratamiento temático).

- Emoción y sentimentalismo (por encima de la racionalidad).

2 Algunos de estos indicios (como la personalización, el dramatismo o la tendencia a la emoción) coinciden, de hecho, con elementos del lenguaje del infoentretenimiento (cfr. Carrillo, 2013: 50), lo cual consideramos que refuerza la utilidad de este listado de índices para el estudio del infotainment. 
- Dramatización, exageración de la gravedad de los acontecimientos y acentuación de los aspectos trágicos

- Búsqueda de la acción (violencia, sufrimiento...), por encima de ideas o explicaciones.

- Presencia o mención de imágenes espectaculares (incendios, disturbios, violencia callejera, catástrofes, guerras).

- Sucesos

La muestra que utilizamos parte de los materiales analizados en el proyecto de investigación TEDEPO durante el período 2008-2011. Este proyecto realizó un análisis triple: programación, noticiarios e infotainment en ocho canales de televisión de ámbito estatal y autonómico; en el presente artículo se presentan datos relativos a los dos últimos géneros mencionados.

Por lo que respecta a los datos de los noticiarios, proceden de los informativos Notícies 9, edición noche, de Canal 9, y Canal Sur Noticias 2, de Canal Sur Televisión (en su versión de emisión vía satélite, Andalucía Televisión). En ambos casos, se trata de los informativos enprime-time. Los días de emisión corresponden al período que va desde el 8 de abril de 2010 al 22 del mismo mes. Los contenidos fruto del análisis de los informativos de Canal 9 han sido agrupados en 6 grandes bloques temáticos donde pueden hallarse contenidos susceptibles de espectacularización: las medidas económicas adoptadas por el Gobierno central en relación con la Comunidad Valenciana, el Caso "El Cabanyal", el trasvase Tajo-Segura, el Estatuto de Catalunya, el Caso Garzón, y la corrupción. En el caso de Canal Sur, la información también se ha agrupado en 6 bloques temáticos, pero algunos de ellos difieren respecto a la cadena valenciana: medidas gubernamentales (de distintos niveles en la administración política española), situación socioeconómica e inmigración, política nacional e internacional, la trama Gürtel, Garzón, y la corrupción. Tanto en el caso de los informativos de Canal 9 como en el de los de Canal Sur, las unidades de registro (cfr. Krippendorff, 2004: 99) han sido los titulares que resumen las noticias; por ejemplo, "Cargas policiales en el Cabanyal" (Canal Sur, 18 de abril de 2010) sería una unidad de este tipo. Asimismo, la información procedente de ambos noticiarios versa sobre un número misceláneo de temas relacionados directa o indirectamente con la política: crisis económica, medidas económicas, inmobiliaria y construcción, agua y gestión de recursos hídricos, política europea, etc.

En cuanto a los contenidos de infotainment, hemos trabajado con información codificada a partir de 10 programas ( 5 pertenecientes a cadenas privadas, y 5 a públicas) emitidos entre el 8 y el 14 de abril de 2010: Ana Rosa (Telecinco, emitido el 9 de abril de 2010), Espejo Público (Antena 3, 8 de abril de 2010), Mañanas Cuatro (Cuatro, 8 de abril de 2010), Los Desayunos (TVE1, 8 de abril de 2010), El Meridiano (Canal Sur, 8 de abril de 2010), La Tertúlia (Canal 9, 13 de abril de 2010), ElsMatins (TV3, 8 de abril de 2010), Debate al límite (La Sexta, 9 de abril de 2010), 59 segundos (TVE1, 14 de abril de 2010) y La Noria (Telecinco, 10 de abril de 2010). En estos programas se seleccionaron los bloques informativos que versaban sobre política, y dichos bloques fueron divididos en tramas. Nuestro análisis de contenido versa sobre 4 
grandes bloques temáticos que engloban a la mayoría de estas tramas: el caso Gürtel, la corrupción, Garzón, y la desafección política. Las tramas (codificadas con un formato como el del siguiente ejemplo: "Presentador dice que los políticos son la tercera preocupación de los ciudadanos") van a ser entendidas como las unidades de registro en esta parte del análisis.

\section{Resultados}

Comenzaremos este apartado exponiendo los resultados referentes a la espectacularización y dramatización de la agenda temática en los dos principales canales autonómicos estudiados. En el caso de los informativos de Canal 9 se encontraron 74 titulares que presentaban indicios de espectacularización. Los datos se reflejan en la Tabla 1:

\begin{tabular}{|c|c|c|c|c|c|c|c|}
\hline $\begin{array}{l}\text { Indicios de } \\
\text { espectacularización }\end{array}$ & $\begin{array}{l}\text { Trama 1: } \\
\text { Medidas } \\
\text { económicas } \\
\text { Gobierno } \\
\text { central- } \\
\text { Generalitat } \\
\text { (frecuencias) }\end{array}$ & $\begin{array}{l}\text { Trama 2: } \\
\text { Caso ' } E l \\
\text { Cabamyal' } \\
\text { (frecuencias) }\end{array}$ & $\begin{array}{l}\text { Trama 3: } \\
\text { Transwase } \\
\text { Tajo-Segura } \\
\text { (frecuencias) }\end{array}$ & $\begin{array}{l}\text { Trama 4: } \\
\text { Estatuto de } \\
\text { Catalumya } \\
\text { (frecuencias) }\end{array}$ & $\begin{array}{l}\text { Trama 5: } \\
\text { Caso } \\
\text { Garzón } \\
\text { (frecuencias) }\end{array}$ & $\begin{array}{l}\text { Trama 6: } \\
\text { Corrupción } \\
\text { (frecuencias) }\end{array}$ & $\begin{array}{l}\text { Total de } \\
\text { indicios } \\
\text { (frecuencias } \\
\text { y } \\
\text { porcentajes) }\end{array}$ \\
\hline \multicolumn{8}{|l|}{$\begin{array}{l}\text { Contenidos de sofi } \\
\text { news }\end{array}$} \\
\hline Famosos & 0 & 0 & 0 & 0 & 0 & 0 & $0(0 \%)$ \\
\hline Delincuencia & 0 & 0 & 0 & 0 & 0 & 0 & $0(0 \%)$ \\
\hline Corrupción & 0 & 0 & 0 & 0 & 0 & 11 & $11(8,2 \%)$ \\
\hline Crimen & 0 & 0 & 0 & 0 & 0 & 0 & $0(0 \%)$ \\
\hline $\begin{array}{l}\text { Búsqueda de la parte } \\
\text { más "humana" de la } \\
\text { información }\end{array}$ & 0 & 0 & 0 & 0 & 0 & 0 & $0(0 \%)$ \\
\hline $\begin{array}{l}\text { Personalización de } \\
\text { los temas }\end{array}$ & 0 & 0 & 24 & 4 & 9 & 0 & $37(27,6 \%)$ \\
\hline Sensacionalismo & 1 & 1 & 0 & 0 & 0 & 0 & $2(1,49 \%)$ \\
\hline Escándalo & 0 & 1 & 0 & 0 & 0 & 4 & $5(3.73 \%)$ \\
\hline $\begin{array}{l}\text { Vida social y mundo } \\
\text { de la farándula }\end{array}$ & 0 & 0 & 0 & 0 & 0 & 0 & $0(0 \%)$ \\
\hline $\begin{array}{l}\text { Banalización y } \\
\text { trivialidad }\end{array}$ & 0 & 0 & 0 & 0 & 0 & 0 & $0(0 \%)$ \\
\hline Lo anecdótico & 0 & 1 & 0 & 0 & 0 & 0 & $1(0,7 \%)$ \\
\hline Superficialidad & 0 & 0 & 0 & 0 & 0 & 0 & $0(0 \%)$ \\
\hline $\begin{array}{l}\text { Emoción y } \\
\text { sentimentalismo }\end{array}$ & 0 & 0 & 22 & 8 & 0 & 0 & $30(22,3 \%)$ \\
\hline $\begin{array}{l}\text { Dramatización, } \\
\text { exageración de la } \\
\text { gravedad de los } \\
\text { acontecimientos y } \\
\text { acentuación de los } \\
\text { aspectos trágicos }\end{array}$ & 0 & 4 & 18 & 2 & 13 & 0 & $37(27,6 \%)$ \\
\hline $\begin{array}{l}\text { Búsqueda de la } \\
\text { acción (violencia, } \\
\text { sufrimiento...). }\end{array}$ & 0 & 0 & 0 & 0 & 0 & 0 & $0(0 \%)$ \\
\hline $\begin{array}{l}\text { Presencia o mención } \\
\text { de imágenes } \\
\text { espectaculares }\end{array}$ & 0 & 1 & 0 & 0 & 0 & 0 & $1(0,7 \%)$ \\
\hline Sucesos & 0 & 0 & 0 & 0 & 0 & 0 & $0(0 \%)$ \\
\hline $\begin{array}{l}\text { Total de indicios por } \\
\text { Iramas (frecuencias y } \\
\text { porcentajes) }\end{array}$ & $1(0,7 \%)$ & $8(6,45 \%)$ & $64(51,61 \%)$ & $14(11,29 \%)$ & $22(17,74 \%)$ & $15(12,09 \%)$ & $124(100 \%)$ \\
\hline
\end{tabular}

Tres indicadores de espectacularización destacan en la tabla: la personalización de los temas, la tendencia a la dramatización, y, en menor medida, la explotación de la 
emoción y el sentimentalismo. Estos tres aspectos engloban casi el $84 \%$ del total de unidades de análisis extraídas de los informativos de Canal 9. No se trata de contenidos de soft news en sentido estricto (con la excepción de la corrupción, dichos contenidos no aparecen en la información periodística del canal), pero llama la atención, por ejemplo, que cuestiones socioeconómicas como el trasvase Tajo-Segura presenten un porcentaje de indicios de personalización muy superior al de bloques temáticos como el del caso Garzón, referido per se a un individuo concreto. La tendencia a la dramatización, por otro lado, implica cierta tendencia a la exageración, lo cual podría verse en el caso del informativo correspondiente al 9 de abril de 2010, donde el gobierno valenciano interpreta como un ataque a los intereses de los valencianos el anuncio del Consejo de Ministros de un recurso a la ley valenciana que ampara los derribos de algunas casas de propiedad municipal, situadas fuera de la zona protegida de El Cabanyal. Por otro lado, una lectura vertical (por bloques temáticos) de la Tabla 1 indica que la ya citada cuestión del trasvase Tajo-Segura es el bloque más susceptible de ser espectacularizado y dramatizado, al recoger más de la mitad de los titulares que presentan indicios de este tipo. El uso de la emoción y el sentimentalismo en el bloque temático del Estatuto de Catalunya, la dramatización/exageración del caso Garzón, o la tendencia al sentimentalismo en el trasvase Tajo-Segura, son otros aspectos que destacan cuantitativamente en una lectura vertical.

En cuanto a los informativos de Canal Sur, encontramos en total 65 titulares susceptibles de ser interpretados en función de indicios de espectacularización. Los datos pueden verse en la Tabla 2:

\begin{tabular}{|c|c|c|c|c|c|c|c|}
\hline $\begin{array}{l}\text { Indicios de } \\
\text { espectacularización }\end{array}$ & $\begin{array}{l}\text { Trama 1: } \\
\text { Medidas de } \\
\text { gobiernos de } \\
\text { distintos } \\
\text { niveles } \\
\text { (frecuencias) }\end{array}$ & $\begin{array}{l}\text { Trama 2: } \\
\text { Situación } \\
\text { socio- } \\
\text { económica e } \\
\text { inmigración } \\
\text { (frecuencias) }\end{array}$ & $\begin{array}{l}\text { Trama 3: } \\
\text { Politica } \\
\text { nacional e } \\
\text { internacio- } \\
\text { nal } \\
\text { (frecuencias) } \\
\end{array}$ & $\begin{array}{l}\text { Trama 4: } \\
\text { Gïriel } \\
\text { (frecuencias) }\end{array}$ & $\begin{array}{l}\text { Trama 5: } \\
\text { Garzón } \\
\text { (frecuencias) }\end{array}$ & $\begin{array}{l}\text { Trama 6: } \\
\text { Corrupción } \\
\text { (frecuencias) }\end{array}$ & $\begin{array}{l}\text { Tolal de } \\
\text { indicios } \\
\text { (frecuencias } \\
\text { y } \\
\text { porcentajes) }\end{array}$ \\
\hline \multicolumn{8}{|l|}{$\begin{array}{l}\text { Contenidos de soft } \\
\text { news }\end{array}$} \\
\hline Famosos & 0 & 0 & 0 & 0 & 0 & 0 & $0(0 \%)$ \\
\hline Delincuencia & 2 & 2 & 2 & 0 & 0 & 0 & $6(7.5 \%)$ \\
\hline Corrupción & 0 & 0 & 0 & 0 & 0 & 2 & $2(2,5 \%)$ \\
\hline Crimen & 0 & 0 & 0 & 0 & 0 & 0 & $0(0 \%)$ \\
\hline $\begin{array}{l}\text { Búsqueda de la parte } \\
\text { más "humana" de la } \\
\text { información }\end{array}$ & 0 & 0 & 1 & 0 & 0 & 0 & $1(1,2 \%)$ \\
\hline $\begin{array}{l}\text { Personalización de los } \\
\text { temas }\end{array}$ & 4 & 2 & 8 & 9 & 4 & 8 & $35(44,3 \%)$ \\
\hline Sensacionalismo & 1 & 4 & 1 & 1 & 1 & 1 & $9(11,3 \%)$ \\
\hline Escándalo & 1 & 1 & 0 & 1 & 0 & 0 & $3(3,7 \%)$ \\
\hline $\begin{array}{l}\text { Vida social y mundo de } \\
\text { la farándula }\end{array}$ & 0 & 0 & 0 & 0 & 0 & 0 & $0(0 \%)$ \\
\hline $\begin{array}{l}\text { Banalización y } \\
\text { trivialidad }\end{array}$ & 0 & 0 & 0 & 0 & 0 & 0 & $0(0 \%)$ \\
\hline Lo anecdótico & 0 & 0 & 0 & 0 & 0 & 0 & $0(0 \%)$ \\
\hline Superficialidad & 0 & 1 & 0 & 0 & 0 & 0 & $1(1,2 \%)$ \\
\hline $\begin{array}{l}\text { Emoción y } \\
\text { sentimentalismo }\end{array}$ & 1 & 0 & 1 & 0 & 0 & 0 & $2(2,5 \%)$ \\
\hline $\begin{array}{l}\text { Dramatización, } \\
\text { exageración de la } \\
\text { gravedad de los } \\
\text { acontecimientos y } \\
\text { acentuación de los } \\
\text { aspectos trágicos }\end{array}$ & 0 & 5 & 0 & 0 & 1 & 0 & $6(7,5 \%)$ \\
\hline
\end{tabular}




\begin{tabular}{|c|c|c|c|c|c|c|c|}
\hline $\begin{array}{l}\text { Búsqueda de la acción } \\
\text { (violencia, } \\
\text { sufrimiento...). }\end{array}$ & 0 & 5 & 0 & 0 & 0 & 0 & $5(6,3 \%)$ \\
\hline $\begin{array}{l}\text { Presencia o mención de } \\
\text { imágenes } \\
\text { espectaculares }\end{array}$ & 4 & 5 & 0 & 0 & 0 & 0 & $9(11,3 \%)$ \\
\hline Sucesos & 0 & 0 & 0 & 0 & 0 & 0 & $0(0 \%)$ \\
\hline $\begin{array}{l}\text { Total respecto a tramas } \\
\text { (frecuencias y } \\
\text { porcentajes) }\end{array}$ & $13(16,4 \%)$ & $25(31,6 \%)$ & $13(16,4 \%)$ & $11(13,9 \%)$ & $6(7,5 \%)$ & $11(13,9 \%)$ & $79(100 \%)$ \\
\hline
\end{tabular}

Estos datos evidencian que, como ocurre con Canal 9, la comunicación periodística de Canal Sur tiende de forma estructural a la personalización de los temas. Y no sólo se da en un porcentaje global muy considerable $(44,3 \%)$, sino que se produce de forma transversal, afectando a todos los bloques temáticos en que puede agruparse la información codificada. Otros indicios de espectacularización que cuentan con peso cuantitativo en Canal Sur son el sensacionalismo y las imágenes espectaculares (ambos ítems alcanzan más del 10\%), seguidos por los contenidos sobre delincuencia y el indicio de la dramatización (ambos con una frecuencia del 7,5\%). Una lectura vertical de la tabla, por otro lado, permite observar que los bloques temáticos más directamente relacionados con la realidad política (situación socioeconómica e inmigración, medidas gubernamentales, y política nacional e internacional) son los más espectacularizados. Llama la atención, por ejemplo, que bloques temáticos como la corrupción o la trama Gürtel (de los que podría pensarse a priori que son materia para una exaltación periodística especialmente sensacionalista) alcancen individualmente menos de la mitad de indicios de espectacularización que las informaciones sobre situación socioeconómica e inmigración. Este último bloque, por cierto, destaca asimismo en una lectura vertical por el número de ítems de espectacularización de los que presenta ejemplos, 8 en total, mientras que, por ejemplo, las noticias sobre la trama Gürtel sólo son afectadas por 3 indicios.

En cuanto a los resultados referentes al infotainment (Tabla 3), encontramos 105 tramas susceptibles de incurrir en el fenómeno de la espectacularización³.

\begin{tabular}{|c|c|c|c|c|c|}
\hline Indicios de espectacularización & $\begin{array}{l}\text { Trama 1: } \\
\text { Gïrtel } \\
\text { (frecuencias) }\end{array}$ & $\begin{array}{l}\text { Trama 2: } \\
\text { corrupción } \\
\text { (frecuencias) }\end{array}$ & $\begin{array}{l}\text { Trama 3: } \\
\text { Garzón } \\
\text { (frecuencias) }\end{array}$ & $\begin{array}{l}\text { Trama 4: } \\
\text { desafección } \\
\text { politica } \\
\text { (frecuencias) }\end{array}$ & $\begin{array}{l}\text { Total de indicios } \\
\text { (frecuencias y } \\
\text { porcentajes) }\end{array}$ \\
\hline \multicolumn{6}{|l|}{ Contenidos de soft news } \\
\hline Famosos & 0 & 0 & 0 & 0 & $0(0 \%)$ \\
\hline Delincuencia & 8 & 8 & 2 & 0 & $18(17,14 \%)$ \\
\hline Corrupción & 15 & 29 & 0 & 0 & $44(41,90 \%)$ \\
\hline Crimen & 2 & 0 & 3 & 0 & $5(4,76 \%)$ \\
\hline $\begin{array}{l}\text { Bủsqueda de la parte más "humana" } \\
\text { de la información }\end{array}$ & 0 & 1 & 2 & 0 & $3(2,85 \%)$ \\
\hline Personalización de los temas & 11 & 5 & 2 & 0 & $18(17,14 \%)$ \\
\hline Sensacionalismo & 16 & 11 & 4 & 2 & $33(31,42 \%)$ \\
\hline
\end{tabular}

${ }^{3}$ La cifra del total de indicios en la tabla (148) no coincide con la de 105 tramas que indican espectacularización porque en varios casos (43, exactamente) las tramas participaban de más de un indicio de espectacularización. 


\begin{tabular}{|c|c|c|c|c|c|}
\hline Escándalo & 2 & 1 & 1 & 0 & $4(3,80 \%)$ \\
\hline Vida social y mundo de la farándula & 0 & 0 & 0 & 0 & $0(0 \%)$ \\
\hline Banalización y trivialidad & 1 & 0 & 0 & 1 & $2(1,90 \%)$ \\
\hline Lo anecdótico & 0 & 0 & 0 & 0 & $0(0 \%)$ \\
\hline Superficialidad & 2 & 2 & 0 & 0 & $4(3,80 \%)$ \\
\hline Emoción y sentimentalismo & 2 & 4 & 0 & 0 & $6(5,71 \%)$ \\
\hline $\begin{array}{l}\text { Dramatización, exageración de la } \\
\text { gravedad de los acontecimientos y } \\
\text { acentuación de los aspectos trágicos }\end{array}$ & 0 & 2 & 3 & 0 & $5(4,76 \%)$ \\
\hline $\begin{array}{l}\text { Búsqueda de la acción (violencia, } \\
\text { sufrimiento...). }\end{array}$ & 0 & 0 & 3 & 0 & $3(2,85 \%)$ \\
\hline $\begin{array}{l}\text { Presencia o mención de imágenes } \\
\text { espectaculares }\end{array}$ & 0 & 1 & 2 & 0 & $3(2,85 \%)$ \\
\hline Sucesos & 0 & 0 & 0 & 0 & $0(0 \%)$ \\
\hline $\begin{array}{l}\text { Total respecto a tramas (frecuencias } \\
\text { y porcentajes) }\end{array}$ & $59(39,86 \%)$ & $64(43,24 \%)$ & $22(14,86 \%)$ & $3(2,02 \%)$ & $148(100 \%)$ \\
\hline
\end{tabular}

Tabla 3. Frecuencias y porcentajes de los indicios de espectacularización en los programas de infotainment.

Los datos de la Tabla 3 evidencian que los contenidos de soft news sí son relevantes para entender el enfoque temático del infotainment; sobre todo, las cuestiones de corrupción y delincuencia. En la tertulia del informativo matinal Notícies 9 edició Bon dia, por ejemplo, se trata la idea de que la corrupción es la tercera preocupación de los ciudadanos. No obstante, la cuestión de la corrupción podía ser algo previsible, al fin y al cabo, dada la naturaleza de dos de las tramas políticas objeto de estudio. Más interesante es que los contenidos relativos a la delincuencia arrojen un 17,14\% de frecuencia, con lo que se convierten en el tercer ítem más reiterado (junto a la cuestión de la personalización) en el material que analizamos. Cuantitativamente debe destacarse asimismo la importancia del enfoque sensacionalista (es decir, un enfoque de la información que no se atiene a juicios calibrados), que aparece en casi un tercio $(31,42 \%)$ de las tramas de los programas. La mezcla de delincuencia y enfoque sensacionalista puede explicar, por ejemplo, que en El Meridiano, de Canal Sur (8 de abril de 2010), se escuchen expresiones como "[...] arte del choriceo [...]", "[...] dinero sucio y bruto[...]", "[...] minutos basura de la política[...]", o "¿[...] esto es un estado policial o un estado de Derecho?".

También es destacable en el infotainment el concepto de la personalización, que afecta a un $17,14 \%$ de las tramas políticas en los programas estudiados. Una muestra de ello es, en el caso de Canal 9, el hecho de que de los tres temas del sumario de la tertulia de Notícies 9 edició Bon dia del 13 de abril de 2010, los dos primeros se caracterizan por un enfoque claramente personalizado: «Manos limpias denuncia a Garzón por presunta prevaricación» $\mathrm{y}$ «Rita Barberà amenazada de muerte por los derribos de El Cabanyal». Es más, en el desarrollo de estos contenidos durante el programa, al primero de estos temas se le dedican veinte minutos de duración, de los cuales más de la mitad corresponden a una entrevista al secretario general del Sindicato Manos Limpias, Miguel Bernard, a quien, supuestamente, y mediante un dúplex, se incorpora como tertuliano desde Madrid, pero al que el conductor del programa entrevista durante trece minutos dando todo tipo de detalles de la querella por presunta prevaricación contra el juez Garzón. Es en los cinco minutos últimos del bloque, y tras despedir al invitado, cuando los periodistas-tertulianos presentes en el plató comentan las declaraciones de Bernard. 
Si ponemos en común los datos de los informativos y de los programas de infotainment, observamos un punto común crucial: la cuestión de la personalización, que es el indicador de espectacularización más frecuente en los informativos (junto a la dramatización en el caso de Canal 9), y uno de los más frecuentes en el infotainment. Por otro lado, llama la atención que la importancia que tiene la dramatización en los informativos de Canal 9 no se vea reflejada ni en los informativos de Canal Sur ni en el infoentretenimiento de las televisiones españolas ( $27,6 \%$ frente al $7,5 \%$ y el $4,76 \%$, respectivamente). Comparativamente, merece asimismo la pena apuntar que el sensacionalismo, que es fundamental en el infotainment, apenas aparece en los informativos de Canal 9, donde alcanza un prácticamente irrelevante 1,49\% de frecuencia; pero sí tiene más importancia en el caso de Canal Sur, donde alcanza el 11,3\%. Por otro lado, una lectura vertical de las tablas indica que la información más espectacularizada en los informativos atiende a cuestiones socioeconómicas en general, mientras que en las tertulias de infoentretenimiento el tema líder en espectacularización resulta ser la corrupción $(43,24 \%)$.

Desde el punto de vista del tratamiento de los bloques temáticos, los únicos bloques que aparecen de forma recurrente en las distintas agendas temáticas de Canal 9 y Canal Sur, es decir, la trama Gürtel y el caso del juez Garzón, tienen un peso considerable en la información espectacularizada de Canal 9, pero no tanto en la de Canal Sur. Los contenidos espectacularizados sobre corrupción, por otro lado, aparecen como un elemento llamativo tanto en los informativos como en el infotainment, si bien de manera mucho menos acentuada en los informativos de Canal Sur.

\section{Discusión}

Aunque las condiciones muestrales de esta investigación nos llevan a ser cautelosos a la hora de generalizar los resultados, nuestros datos pueden entenderse como una ilustración sincrónica de la presencia de indicios de espectacularización y dramatización en los informativos de Canal Sur y Canal 9. Presencia que se encuentra en línea con lo observado, más en general, por Díaz Nosty: "Los espacios noticiosos de la televisión se han espectacularizado en los últimos años, lo que supone un empobrecimiento en sus contenidos, rigor y variedad temática" (2006: 23).

A raíz de los resultados recogidos, en primer lugar encontramos que, con la excepción de la personalización de los temas, los indicios de espectacularización no aparecen de forma homogénea en los canales estudiados. Mientras que la información de Canal Sur tiende mayoritariamente a indicios como el sensacionalismo y las imágenes espectaculares, la de Canal 9 tiende a la dramatización y el sentimentalismo. En cualquier caso, merece la pena apuntar que la tendencia a la dramatización (un concepto estrechamente relacionado con el de espectacularización) también está presente en Canal Sur, si bien en menor grado que en la cadena valenciana.

La personalización de los temas (es decir, la individualización de las cuestiones tratadas) resulta ser el indicador de espectacularización más usado en los informativos, con porcentajes del 27,6\% en Canal 9 y del 44,3\% en Canal Sur. En este contexto, nuestros datos están en línea con un estudio sobre la edición nocturna de Noticias Cuatro, que ya indicaba "una clara tendencia hacia la personalización de los temas, 
buscando siempre el lado más humano para confeccionar las noticias" (Ortells Badenes, 2009). Por otro lado, la relevancia de este indicio de espectacularización está en línea con la idea de que la televisión ha contribuido a la personalización de la política (cfr. Martín Salgado, 2002: 95). La personalización es un recurso retórico, una estrategia discursiva a la que, probablemente, se recurre con tanta frecuencia porque permite focalizar la atención en un individuo, con frecuencia un líder político determinado (en los casos analizados, el president de la Generalitat, Francisco Camps, o la alcaldesa de Valencia, Rita Barberà, por ejemplo) o un nombre de actualidad (el juez Baltasar Garzón o el extesorero del Partido Popular, Luis Bárcenas), con el fin de ensalzar su figura o de desdeñarla, de connotarla bien de forma positiva o bien negativa. Otras veces, esta focalización se produce sobre un sujeto colectivo, como ocurre con las supuestas discriminaciones a los "regantes valencianos" por las reservas hídricas del Estatuto de Castilla-La Mancha o las del Estatut de Catalunya con respecto a otras autonomías, como la valenciana, lo que "obliga" al gobierno valenciano a exigir los mismos privilegios que contiene el reformado estatuto catalán.

En resumen, la respuesta a $\mathrm{PI}_{1}$ está centrada sobre todo en la cuestión de la personalización de la información política, con los elementos adicionales de la dramatización, el sentimentalismo, el sensacionalismo y las imágenes espectaculares. En este contexto, llama la atención que el tema más sometido a la espectacularización en los informativos sea el del trasvase Tajo-Segura (un tema donde están en juego cuestiones sociales de calado, como las desigualdades y la solidaridad entre comunidades), lo que indica que el tratamiento de temas serios no está tampoco exento de sentimentalismo y dramatización. Por otro lado, y debido a la escasa relevancia cuantitativa que tienen los contenidos de soft news en Canal 9 y Canal Sur, nuestros datos no se ajustarían del todo a la idea de Thussu del "global infotainment" como la globalización de un periodismo televisivo de inspiración estadounidense que privilegia las soft news (cfr. 2009: 8).

Los contenidos de soft news sí tienen una presencia relevante en el infotainment. Aquí, la importancia del enfoque sensacionalista puede verse influida por el hecho de que en dicha muestra constan, en particular, dos programas de Telecinco, cadena que desde 2000 ha apostado por una televisión polémica (cfr. Artero Muñoz, 2007: 267). Dados sus imperativos comerciales, no debería ser motivo de asombro que las cadenas privadas tiendan a las soft news y lo sensacional; ahora bien, que una muestra sobre infoentretenimiento donde constan 4 cadenas públicas arroje un $31,42 \%$ de indicios de sensacionalismo, puede señalar que los canales públicos no son inmunes a la lógica de la espectacularización. Máxime cuando, en paralelo, al menos uno de los informativos estudiados (Canal Sur) presenta asimismo ciertas tendencias sensacionalistas. En este sentido, no debe olvidarse la tendencia contextual en la televisión europea a la difuminación de fronteras entre las emisoras de servicio público y las comerciales (cfr. Thussu, 2009: 41-42).

Por otro lado, nuestros datos no están en línea con la idea de que el infoentretenimiento tiende a tratar temas sensacionalistas relegando a un lugar secundario las noticias políticas (cfr. Ortells Badenes, 2009): los datos revelan que, en este género híbrido, la política no es dejada de lado, sino que se convierte en un objeto perfecta- 
mente adaptable a la lógica sensacionalista. En este punto es necesario incidir en cómo las televisiones públicas autonómicas se han mirado con excesiva frecuencia en el espejo de las programaciones comerciales a la hora de construir sus parrillas de programación, siguiendo en muchos casos la lógica televisiva de copiar aquello que funciona para ganar audiencia (cfr. Hill, 2005) y ahondando, en consecuencia, en el modelo de la espectacularización, independientemente del carácter público o privado y de la función social asignada. El programa Tómbola, que impulsó Canal9 y que Canal Sur llegó a programar entre marzo y julio de 1997, así como los distintos formatos derivados del folklorismo de este último, son una buena muestra de ello.

Desde un punto de vista comparativo, la respuesta a $\mathrm{PI}_{2}$ sería que los programas informativos y los de infoentretenimiento presentan puntos de contacto, pero también diferencias. Por consiguiente, y teniendo en cuenta la hipótesis relativa a la existencia de indicios similares de espectacularización en los informativos y en el infotainment, la respuesta es que la hipótesis se cumple sólo en parte: la personalización, por ejemplo, resulta clave en ambos géneros, pero existen diferencias respecto a otros indicios de espectacularización, como el sensacionalismo. Respecto a este último, podría decirse que los informativos de Canal Sur se parecen más al modelo del infoshow, ya que ambos comparten el enfoque sensacionalista, si bien en distinta medida.

Aunque los datos procesados podrían indicar que los noticiarios de televisión españoles aún no se han plegado completamente a los contenidos de soft news (o, al menos, no tanto como lo ha hecho el infoentretenimiento español), consideramos no obstante que los informativos están lo suficientemente influidos por la tendencia a la espectacularización como para que la respuesta a $\mathrm{PI}_{3}$ (que preguntaba por la imagen de la política surgida a partir de los contenidos informativos y el infotainment) nos lleve a reflexionar. La imagen de la política generada por la información no ofrece enormes diferencias respecto a la generada por el infotainment, si bien en este último caso emerge una aún más inquietante representación de la política centrada en aspectos como la corrupción, el sensacionalismo y la delincuencia. Lo cual no tendría que ser negativo per se, siempre que este tipo de aspectos se traten correctamente; el problema es el tratamiento que el infotainment otorga a la información de interés general. En este tipo de programas, por ejemplo, las tramas sobre corrupción evidencian la presencia de elementos sentimentalistas hasta en 6 ocasiones; lo cual nos parece un punto criticable, máxime cuando temas como la corrupción (directamente relacionados con los asuntos públicos) deberían ser objeto de una crítica racional y democrática, en lugar de un espacio para apelaciones emocionales.

Por otra parte, también constatamos en algunos casos coincidencias temáticas entre los contenidos de los espacios informativos de referencia y los de los programas incluidos en el infotainment. Esto, que atendiendo a la coherencia editorial propia del medio sería lógico, resulta cuando menos llamativo, ya que la coincidencia va más allá del tema, justificado por su actualidad y relevancia, sino que se manifiesta, además de en la selección y jerarquización, en el enfoque de los mismos; unos enfoques tendentes a la dramatización y la espectacularización. Por ejemplo, la tertulia del Notícies 9 Bon dia, de hecho, parece presentar un correlato de la agenda temática de los informativos, lo cual podría indicar una determinada estrategia comunicativa por parte de 
Canal 9, donde se mezclan la dramatización y la orientación política (entre otros aspectos, aparece la idea de que la reforma laboral facilitará el despido, en un contexto donde el gobierno español aún estaba en manos del PSOE). En cualquier caso, en lo relativo a la coincidencia temática se mantienen algunas diferencias en el tratamiento espectacular entre los dos géneros estudiados: la trama de "corrupción", por ejemplo, que aparece en las tres tablas, es objeto de enfoque sensacionalista en 11 ocasiones en los programas de infoentretenimiento, pero dicho enfoque aparece sólo una vez en el caso de los informativos de Canal Sur, y ninguna en el caso de los de Canal 9.

\section{Conclusiones}

A raíz de los resultados obtenidos en la investigación sobre informativos e infotainment, podemos concluir en primer lugar que la representación de la agenda temática de la información política en ambos géneros tiende de forma notable a la espectacularización. La cuestión es que dicha espectacularización no se lleva a cabo en función de los mismos elementos, ni en el caso de los informativos en sí mismos, ni en lo relativo a su comparación con los programas de infoentretenimiento. La tendencia a la espectacularización se manifiesta a través de distintos indicadores; fundamentalmente, y en el caso de los informativos, mediante el recurso a la personalización (el indicio más importante de todos), la dramatización, el sentimentalismo y el sensacionalismo. En cualquier caso, y aunque la personalización parece ser un indicio estructural, existen diferencias entre los informativos y el infotainment a la hora de representar la actualidad política; diferencias basadas en aspectos como la preeminencia de los contenidos de soft news en el infoentretenimiento.

En segundo lugar, y por lo que respecta específicamente al infotainment, también hemos constatado que las cadenas públicas parecen haber sido arrastradas por la lógica de las privadas en lo relativo al tratamiento de los temas y las distintas manifestaciones de la espectacularización. En este contexto, consideramos interesante seguir profundizando en la investigación de las semejanzas y diferencias que acercan y separan al periodismo "serio" del periodismo de infotainment, ampliando el muestreo, por ejemplo, a programas informativos procedentes de cadenas de televisión privadas. En tercer lugar, también hemos podido confirmar que existe cierta correlación temática entre el tratamiento de los temas en los informativos y en los programas de infotainment. En relación con esta correlación temática, percibimos que emerge un patrón temático en el infoentretenimiento que mezcla contenidos sobre corrupción y delincuencia con un enfoque sensacionalista y personalizado; enfoque que dista mucho del ideal de una información rigurosa, equilibrada y de servicio público, dirigida a una ciudadanía a la que se pretende informada sobre cuestiones relativas al bien común.

Antes de concluir, y a la vista de los resultados obtenidos, nos parece pertinente reclamar con urgencia una reflexión profunda sobre las coordenadas en las que se encuentra actualmente el audiovisual público español dentro del marco general de la comunicación mediática. Una reflexión que, en el contexto actual, habrá de contemplar necesariamente medidas que trasciendan la autorregulación o la desregulación regulada, al menos en aquellos casos en que no existen mecanismos que velen por los derechos de un ciudadano a una información de servicio público, dirigida a un destinatario considerado antes ciudadano que consumidor. 


\section{Referencias bibliográficas}

ALMANSA, Ana (2009): "Los 20 años de Canal Sur", en Anuario Crítico de Almería 2009. Sitio web de la Asociación de Periodistas / Asociación de la Prensa deAlmería: http://www.anuariocritico.es/2009/articulo.php?id=25 [fecha de consulta: 17 de mayo de 2012]

ARTERO MUÑOZ, Juan Pablo (2007): Modelos estratégicos de Telecinco (19902005). Madrid, Fragua.

BERNARDO PANIAGUA, José María y PELLISSER ROSSELL, Nel·lo (2010): "Alternativas a la «espectacularización» televisiva", en LEÓN, Bienvenido (coordinador): Informativos para la televisión del espectáculo. Sevilla - Zamora, Comunicación Social Ediciones y Publicaciones, pp. 30-40.

BIOQUE, Victoria (2008): "Récord histórico de audiencia para «Se llama copla» de Canal Sur", en ABCdesevilla.es, 26 de febrero, sección TVYRADIO:

$\mathrm{http}: / / w w w . a b c d e s e v i l l a . e s /$ hemeroteca/historico-26-02-2008/sevilla/TVyRadio/record-historico-de-audiencia-para-se-11ama-copla-de-canalsur_1641676039552.html [fecha de consulta: 15 de mayo de 2012]

BOURDIEU, Pierre (1997): Sobre la televisión. Barcelona, Anagrama.

CARRILLO, Nereida (2013): "El género-tendencia del infoentretenimiento: definición, características y vías de estudio", en FERRÉ PAVIA, Carme (ed.): Infoentretenimiento. El formato imparable de la era del espectáculo. Barcelona, Editorial UOC, pp. 33-58.

CASETTI, Francesco y DI CHIO, Federico (1999): Análisis de la televisión. Instrumentos, métodos y prácticas de investigación. Barcelona, Paidós.

DÍAZ NOSTY, Bernardo (20064): "Repensar la comunicación. La huella es el mensaje", en Tendencias'06. Medios de comunicación. El año de la televisión. Director del informe: Bernardo Díaz Nosty. Coordinación editorial: José Fernández Beaumont. Fundación Telefónica, pp. 15-43.

ECO, Umberto (1986): La estrategia de la ilusión. Barcelona, Lumen.

FERNÁNDEZ SORIANO, Emelina (1999): Canal Sur, una televisión regional en Europa. Servicio de Publicaciones e Intercambio Científico de la Universidad de Málaga.

GONZALEZ REQUENA, Jesús (1985): “Introducción a una teoría del espectáculo". Revista Telos, no 4, pp. 33-44.

GONZÁLEZ-SANTIAGO, Lalia (2012): "Canal Sur 2 cierra su programación para ahorrar 20 millones de euros", en SUR.es, 5 de septiembre, sección "Local", "Andalucía", http://www.diariosur.es/v/20120905/andalucia/canal-cierra-programacion-para-20120905.html [fecha de consulta: 28 de septiembre de 2013]

4 Fecha del Depósito Legal. 
HILL, Annette (2005): Reality TV. Audiences and popular factual television. Abingdon (Oxon) and New York, Routledge.

IMBERT, Gerard (2008a): El transformismo televisivo. Postelevisión e imaginarios sociales. Madrid, Cátedra.

IMBERT, Gerard (2008b): "Bienvenidos al desierto de lo hiperreal", en El Pais, 1 de noviembre, sección Opinión, en: http://elpais.com/diario/2008/11/01/opinion /1225494004_850215.html [fecha de consulta: 28 de septiembre de 2013]

IMBERT, Gerard (2010): La sociedad informe. Posmodernidad, ambivalencia y juego con los límites. Barcelona, Icaria.

IGARTUA, Juan José (2006): Métodos cuantitativos de investigación en comunicación. Barcelona, Bosch.

KAPUSCINSKI, Ryszard (2002): Los cínicos no sirven para este oficio. Barcelona, Anagrama.

KRIPPENDORFF, Klaus (2004): Content Analysis. An Introduction to Its Methodology. Second Edition. Thousand Oaks (California) Sage Publications.

LEÓN, Bienvenido (2010): "Introducción. Información y espectáculo en un nuevo ecosistema informativo", en LEÓN, Bienvenido (coordinador): Informativos para la televisión del espectáculo. Sevilla • Zamora, Comunicación Social Ediciones y Publicaciones, pp. 17-29.

MARTÍN SALGADO, Lourdes (2002): Marketing politico. Barcelona y Buenos Aires, Paidós.

MANFREDI DÍAZ, Antonio y GARCÍA HERNÁNDEZ, Gabriel (1999): “Canal Sur: 1989-1999". Ámbitos. Revista andaluza de comunicación, no 2 Enero-Junio 1999. Sevilla, Grupo de Investigación en Estructura, Historia y Contenidos de la Comunicación (Universidad de Sevilla) y Asociación Universitaria Comunicación y Cultura, pp. 163-206.

MONTAÑO MONTAÑO, Miguel (1999): "El Canal 2 de Andalucía y la Información Ambiental: el Programa Espacio Protegido". Ámbitos. Revista andaluza de comunicación $\mathrm{n}^{\circ} 2$ Enero-Junio 1999. Sevilla, Grupo de Investigación en Estructura, Historia y Contenidos de la Comunicación (Universidad de Sevilla) y Asociación Universitaria Comunicación y Cultura, pp. 207-227.

MORENO, Isidoro (2000s): "Identidad de las televisiones autonómicas, el espacio de lo próximo en una sociedad globalizada", en VVAA: Nuevos retos para las televisiones y radios autonómicas. $1^{\text {a }}$ jornadas organizadas por el Consejo de Administración de RTVA, pp. 183-189.

ORTELLS BADENES, Sara (2009): “La mercantilización de la información: la nueva era informativa en televisión". RLCS, Revista Latina de Comunicación Social 64.

\footnotetext{
${ }^{5}$ Fecha del Depósito Legal.
} 
La Laguna (Tenerife), Laboratorio de Tecnologías de la Información y Nuevos Análisis de Comunicación Social, pp. 341-353, en: http://www.revistalatinacs .org/09/art/28_827_46_ULEPICC_07/Sara_Ortells.html [fecha de consulta: 27 de febrero de 2012] DOI: $10.4185 /$ RLCS-64-2009-827-341-353

PAVIS, Patrice (2008): El análisis de los espectáculos. Barcelona, Paidós.

POSTMAN, Neil (1991): Divertirse hasta morir. El discurso público en la era del show business, Ediciones de la Tempestad, Barcelona.

PRADO, Emili (2003): “La espectacularización de la realidad", en PÉREZ ORNIA, José Ramón (Dirección y edición): El Anuario de la Televisión 2003. Madrid, Gabinete de Estudios de la Comunicación Audiovisual (GECA), pp. 178-186.

RAMONELL, Mateu (2006): "La televisión autonómica en España". Chasqui. Revista Latinoamericana de Comunicación, $\mathrm{n}^{\circ}$ 93. Quito, Centro Internacional de Estudios Superiores de Comunicación para América Latina, pp. 34-39.

RAMONET, Ignacio (1998): La tiranía de la comunicación. Madrid, Debate.

RAMONET, Ignacio (2000): La golosina visual. Madrid, Debate.

RAMONET, Ignacio (2011): La explosión del periodismo. De los medios de masas a la masa de los medios. Madrid, Clave intelectual.

RTVA (2009): "La televisión andaluza recuerda su historia en «Canal Sur, 20 años»", en página de notas de prensa de Radio Televisión de Andalucía (RTVA), 24 de febrero de 2009: http://blogs.canalsur.es/notasdeprensa/2009/02/24/20-anos/ [fecha de consulta: 13 de abril de 2012]

RTVA (2011): "Récord de audiencia de "Se llama copla: la Gala" en Canal Sur Televisión", en página web de notas de prensa de Radio Televisión de Andalucía, 18 de abril de 2011: http://blogs.canalsur.es/saladeprensa/2011/04/19/record-de-audiencia-de-se-llama-copla-la-gala-en-canal-sur-television/ [fecha de consulta: 15 de mayo de 2012]

TERRASA, Rodrigo (2012): "El cumpleaños de la telebasura", en El Mundo, 12 de marzo, sección C. Valenciana, en:

http://www.elmundo.es/elmundo/2012/03/05/valencia/1330978665.html [fecha de consulta: 28 de septiembre de 2013]

THUSSU, Daya Kishan (2009): News as Entertainment. The Rise of Global Infotainment. London, Sage. 